\title{
Performance analysis of multi-level high voltage direct current converter
}

\author{
Rasha Ghilman Shahin ${ }^{1}$, Hussein Diab Al-Majali²
}

${ }^{1}$ Department of Electrical Engineering, Al Hussein Technical University, Amman, Jordan

${ }^{2}$ Department of Electrical Engineering, Mu'tah University, Mu'tah, Jordan

\begin{tabular}{l} 
Article Info \\
\hline Article history: \\
Received Mar 16, 2021 \\
Revised Sep 9, 2021 \\
Accepted Oct 6, 2021 \\
\hline Keywords: \\
By-pass \\
Characteristics harmonics \\
Multi-level \\
Reactive power
\end{tabular}

Reactive power

\begin{abstract}
The conventional three-phase alternating current (AC) to direct current (DC) converter can be modified using two isolated-gate bipolar transistor (IGBT) as by-pass switches connected to tapping points on the secondary side of the transformer. This scheme yields a reduction in both harmonic contents and reactive volt-ampere absorption. This modified converter possibly eliminates the need for an on-load tap-changer on the converter transformer. The modified AC/DC converter is fully analyzed and implemented under balanced conditions using MATLAB-Simulink. The expressions of the output DC voltage are derived for different cases. The supply current harmonic contents, the reactive power absorption and the power factor have been compared for three schemes; the conventional bridge, the modified bridge using one by-pass IGBT valve and the modified bridge with two bypass IGBT valves.
\end{abstract}

This is an open access article under the $\underline{C C B Y-S A}$ license.

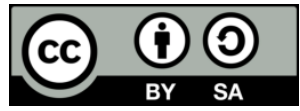

\section{Corresponding Author:}

Hussein Diab Al Majali

Department of Electrical Engineering, Mu'tah University

Al-Karak, 61710, Jordan Township

Email: halmajali@mutah.edu.jo

\section{NOMENCLATURE}

\section{$V_{d} \quad:$ DC Voltage}

$V_{P h}:$ Phase Voltage

$n \quad$ : Transformer tap-section ratio in modified with one IGBT valve

$n_{1}$ : Transformer tap-section ratio of the first tap-section in modified converter with two IGBT valves

$n_{2}$ : Transformer tap-section ratio of the first tap-section in modified converter with two IGBT valves

$X_{C} \quad$ : Main valve commutation reactance

$Q \quad:$ Reactive volt-ampere absorption

$\alpha \quad$ : Delay angle of main thyristor

$\alpha_{0} \quad$ : Delay angle due to unequal valve voltages

$\alpha_{b 1}$ : Turn-on angle of the first by-pass IGBT valve

$\alpha_{b 2}$ : Turn-on angle of the second by-pass IGBT valve

$\alpha_{C 1}$ : Turn-off angle of the first by-pass IGBT valve

$\alpha_{C 2}$ : Turn-off angle of the second by-pass IGBT valve

$\gamma \quad$ : Commutation angle due to main valve

$\gamma_{b 1}$ : Commutation angle due to first IGBT by-pass valve through switch-on

$\gamma_{b 2}$ : Commutation angle due to second IGBT by-pass valve through switch-on

$\gamma_{C 1}$ : Commutation angle due to first IGBT by-pass valve through switch-off

$\gamma_{C 2}$ : Commutation angle due to second IGBT by-pass valve through switch-off 


\section{INTRODUCTION}

The huge advancement in semiconductor technology over the last three decades, especially in alternating current (AC) to direct current (DC) converters that have been used in power conversion applications. The major problems associated with these loads are the harmonic current injection into power supply and volt-ampere absorption. That made providing cheaper and more reliable controlled converters of a crucial importance [1] by improvement of power factor and absorbed volt-ampere reactive (VAR). This is very important issue in any AC system especially in high power applications like high voltage direct current applications (HVDC).

Control of a conventional converters stations, which uses three-phase controlled bridge for converting $\mathrm{AC}$ to $\mathrm{DC}$ is achieved by fast-acting control of the main valves firing angles. But this unfortunately reduces the power factor that should be near unity. This paper presents another algorithm to control the output voltage and improving the power factor.

Tap-changers which are fitted on the converter transformer provide a near constant AC voltage input to the bridge to correct relatively slow changes of AC voltage can be eliminated. Over years several approaches were used to modify the conventional converter, the effect of pulse width modulation (PWM) strategies is used in suppressing both AC harmonics and DC ripples is used [2]-[7]. High pulse converters technique is used in [8]-[10] in these papers high pulse converters like 12, 24, 48 in the HVDC transmission system is used to reduce harmonics in the DC link, but increasing number of pulses yields higher complexity since higher number of components involved.

Filters are used in [11] and [12] these solutions are based on the use of filters that can suppress the higher order harmonics. A voltage control scheme for an HVDC convertor which uses by-pass thyristor valves connected to tapping points on the secondary windings of the transformer is suggested in 1990 in [13]. Fast and continuous control of the DC voltage is possible with good operational characteristics and low values of reactive volt-ampere absorption. The on load tap-changer can be eliminated in this paper.

The technique using combination of two converters is presented in [14]-[16]. O'Kelly [14] proposed a combination of two three-phase thyristor bridges. Two modified series-connected bridges have been used in [15]. The same algorithm as in the previous has been followed in [16] but a voltage control scheme is proposed which uses by-pass gate turn-off transistor (GTO) valves the other one operating as a conventional bridge. GTO thyristor valve sections that has been used may be replaced by thyristors with forcedcommutation circuitry in [17]. The use of a modified three-phase bridge converter which uses GTO thyristors as by-pass valves is suggested in [18] and [19]. It resulted in a reduction in the reactive power absorption. Total harmonic distortion (THD) is reduced by $10 \%$ compared with the conventional full-wave fullycontrolled converter. The power factor of the system was improved.

Many papers these days also tries to improve the HVDC system, an actual view into the development of HVDC converter stations build in modular multilevel converter (MMC) topology is presented in [20]. The reactive power is investigated and controlled at the inverter side of HVDC system that uses line-commutated-converter (LCC) with controllable capacitors in [21]. There are several papers recent studies [22]-[30] have suggested to improve the performance of HVDC converters.

This paper presents a general platform that studies the power systems. Small-signal stability, voltage stability, and interaction phenomena of systems with both line-commutated converter-HVDC (LCC-HVDC) and voltage-source-converter HVDC (VSC-HVDC) can be controlled using feedback control system (FCS) in [31]. A generic root-mean-square (RMS) model of voltage source converter (VSC) in MMC topology for HVDC application is suggested in [32].The modified converter that was implemented in [13] using conventional thyristor as main valves and one GTO as by-pass valve is implemented in this paper using two insulated-gate bipolar transistor (IGBT) as by-pass valves instead of one GTO.

\section{ANALYSIS FOR THE MODIFIED CONVERTER WITH TWO BY-PASS IGBT VALVES}

The block diagram and the schematic diagram of the proposed algorithm using two by-pass IGBT valves are shown in Figure 1 and Figure 2 respectively. Figures 2(a) and 2(b) for conventional bridge, Figures 2(c) and 2(d) for modified bridge. An inductive load consisting of a very large smoothing inductance $(8 \mathrm{H})$ in series with a resistance $(100 \Omega)$ is used in this paper for three schemes conventional converter with one IGBT, and with two IGBTs, connected in series with the output line converter bridge to provide a wellsmoothed DC current to a load connected at the converter output terminals, and to reduce the current transients during system operation. The supply voltage on the side of the transformer was three-phase AC source at $50 \mathrm{~Hz}$ and could be varied from zero to maximum voltage, namely 520 volt line voltage in the three schemes.

Tap-changers which are fitted on the converter transformer provide a near constant AC voltage input to the bridge to correct relatively slow changes of $\mathrm{AC}$ voltage. This approach is not efficient since it is manual and classic. By the modified three-phase AC/DC bridge converters the control of the output voltage 
will be easy and achieved by control of by-pass IGBT valves, firing angles. For normal operation, the main valve thyristor firing angle $\alpha$ is kept near zero, say $\left(5^{\circ}-10^{\circ}\right)$, to give minimum delay between input current and voltage source, i.e., minimum reactive volt-ampere absorption and higher power factor. DC voltage is controlled by variation of turn-on and turn-off angles $\left(\alpha_{b_{1}}, \alpha_{c_{1}}, \alpha_{b_{2}}\right.$, and $\left.\alpha_{c_{2}}\right)$. In practical systems perfect conditions for analysis of characteristic harmonics of a converter are never met, and as a result, harmonics of uncharacteristic orders are produced. Unbalanced operation is studied in [33]-[35]. The transient state is studied in [36], fast and continuous control of a modified HVDC converter [37]. In this paper the steady-state is studied.

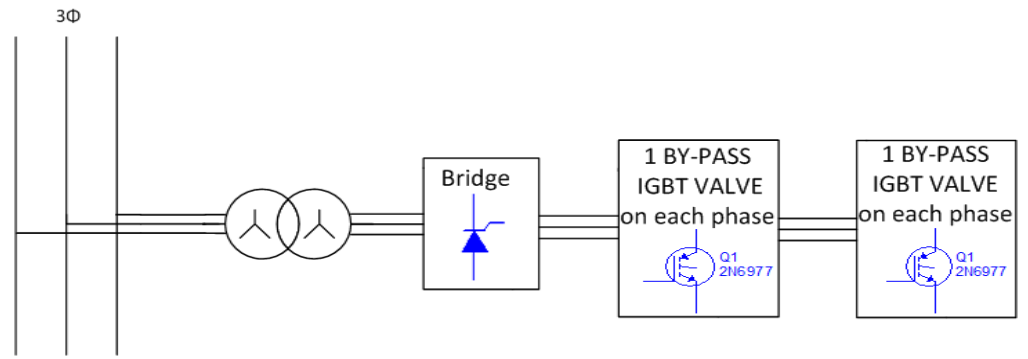

Figure 1. Block diagram of conventional bridge with two by-pass IGBT valves

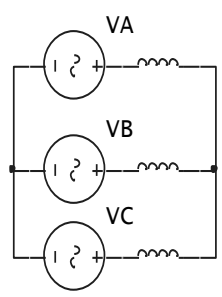

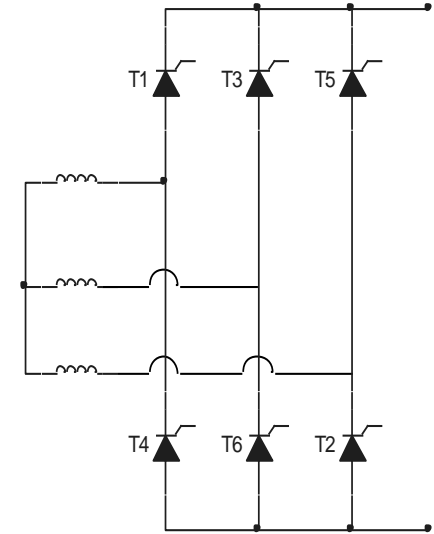

(a)

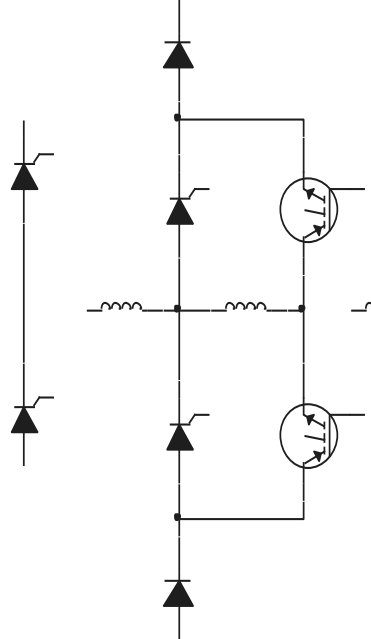

(c)

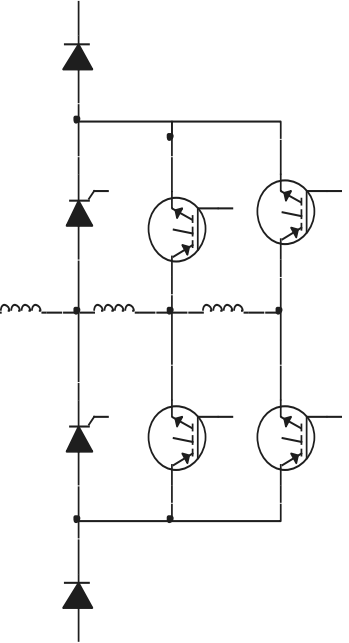

(d)

Figure 2. Alternative schemes for conventional bridge converter: (a) conventional bridge rectifier, (b) one phase of conventional scheme, (c) one phase of alternative scheme using one by pass IGBT valve, and (d) one phase of the proposed scheme using two IGBTs by pass valves

\subsection{Operation under ideal conditions (negligible overlap)}

The average output voltage under ideal conditions of the modified converter, with zero firing angles of the main valves is derived in this paper and is given in (1).

$$
\begin{aligned}
V_{d}=\frac{3}{\pi} \sqrt{6} V_{p h}[1 & +\frac{n_{1}}{2}\left(\cos \alpha_{c_{1}}-\cos \alpha_{b_{1}}\right) \\
& -\frac{n_{1}}{2 \sqrt{3}}\left(\sin \alpha_{c_{1}}-\sin \alpha_{b_{1}}\right) \\
& -\frac{n_{2}}{2}\left(\cos \alpha_{c_{2}}-\cos \alpha_{b_{2}}\right) \\
& \left.+\frac{n_{2}}{2 \sqrt{3}}\left(\sin \alpha_{c_{2}}+\sin \alpha_{b_{2}}\right)\right]
\end{aligned}
$$




\subsection{Finite overlap}

Under finite overlap, $\alpha_{b_{1}}$ can be varied from $-\alpha_{0}$ to $\alpha_{c_{1}}$, and $\alpha_{b_{2}}$ can be varied from $-\alpha_{0}$ to $\alpha_{c_{2}}$. Also $\alpha_{c_{1}}$ and $\alpha_{c_{2}}$ can be varied from $\alpha_{0}+\gamma$ to $\frac{2 \pi}{3}$. So there are several modes of operation for different ranges of $\alpha_{b_{1}}$ and $\alpha_{b_{2}}$.

a. For $\left(-\alpha_{o} \leq \alpha_{b_{1}}<0^{\circ}\right)$ and $\left(0^{\circ}<\alpha_{b_{2}}<\alpha_{c_{1}}\right)$

In this case, the first IGBT by-pass valve is conducting from $-\alpha_{0}+\gamma$ till $\alpha_{b_{2}}$, and is conducting one more time from $\alpha_{c_{2}}$ to $\alpha_{c_{1}}$, but the second IGBT by-pass valve is conducting from $\alpha_{b_{2}}$ to $\alpha_{c_{2}}$. Output DC voltage is given in (2) and the overlap angle $\gamma$ is given in (3). Second commutation occurs between the first and second by-pass valves in the same phase. So $\gamma_{b_{2}}$ is given in (4).

$$
\begin{gathered}
\begin{aligned}
V_{d}=\frac{3}{\pi} \sqrt{2} V_{p h}\left[\frac{3 \sqrt{3}}{4} \cos \left(-\alpha_{b_{1}}+\gamma\right)-\frac{1}{4} \sin \left(-\alpha_{b_{1}}+\gamma\right)\right. \\
+\frac{\sqrt{3}}{2} n_{1} \cos \alpha_{b_{1}}+\frac{1}{2} n_{1} \sin \alpha_{b_{1}} \\
+\frac{\sqrt{3}}{2} n_{1} \cos \left(-\alpha_{b_{1}}+\gamma\right)-\frac{1}{2} n_{1} \sin \left(-\alpha_{b_{1}}+\gamma\right) \\
\quad-\frac{\sqrt{3}}{2} n_{2} \cos \alpha_{c_{2}}+\frac{1}{2} n_{2} \sin \alpha_{c_{2}}+\frac{\sqrt{3}}{2} n_{2} \cos \left(\alpha_{b_{2}}\right. \\
\left.\left.+\gamma_{b_{2}}\right)-\frac{1}{2} n_{2} \sin \left(\alpha_{b_{2}}+\gamma_{b_{2}}\right)\right] \\
\gamma_{b_{2}=} \cos ^{-1}\left[\cos \left(\frac{\pi}{6}+\alpha_{b_{2}}\right)-\frac{x_{b_{2} I_{d}}}{\sqrt{2} n_{2} V_{p h}}\right]-\left(\frac{\pi}{6}+\alpha_{b_{2}}\right) \\
\gamma=\cos ^{-1}\left[\cos \left(\frac{\pi}{6}-\alpha_{b_{1}}\right)-\frac{\left(X_{C}+X_{b_{1}}\right) I_{d}}{\sqrt{6\left(1+n_{1}+\frac{n_{1}{ }^{2}}{3}\right)} V_{p h}}\right]-\left(\frac{\pi}{6}-\alpha_{b_{1}}\right)
\end{aligned}
\end{gathered}
$$

b. For $\left(-\alpha_{o}<\alpha_{b_{2}}<0^{\circ}\right)$ and $\left(\alpha_{c_{1}}>\alpha_{c_{2}}\right)$

In this case the second by-pass IGBT valve is conducting from $-\alpha_{0}+\gamma$ till its $\alpha_{c_{2}}$. Then the first IGBT will conduct $\alpha_{c_{2}}$ till $\alpha_{c_{1}}$, the main thyristor valve will conduct just from $\alpha_{c_{1}}$ to $\left(-\alpha_{b_{2}}+\frac{5 \pi}{6}\right)$. Output DC voltage is given in (4) and the overlap angle $\gamma$ is given in (5).

$$
\begin{aligned}
V_{d}=\frac{3}{\pi} \sqrt{6} V_{p h}\left[\frac{1}{4}\right. & \left(2+n_{1}+n_{2}\right) \cos \left(\gamma-\alpha_{b_{2}}\right) \\
& -\frac{1}{4 \sqrt{3}}\left(n_{1}+n_{2}\right) \sin \left(\gamma-\alpha_{b_{2}}\right) \\
& +\frac{1}{4}\left(3+n_{1}+n_{2}\right) \cos \alpha_{b_{2}} \\
& +\frac{1}{4 \sqrt{3}}\left(n_{1}+n_{2}-1\right) \sin \alpha_{b_{2}}-\frac{1}{2} n_{1} \cos \alpha_{c_{1}} \\
& +\frac{1}{2 \sqrt{3}} n_{1} \sin \alpha_{c_{1}}-\frac{1}{2} n_{2} \cos \alpha_{c_{2}} \\
& \left.+\frac{1}{2 \sqrt{3}} n_{2} \sin \alpha_{c_{2}}\right]
\end{aligned}
$$

c. For $\left(\alpha<\alpha_{b_{1}}<\alpha+\gamma-\gamma_{b_{1}}\right)$ and $\left(\alpha_{b_{1}}<\alpha_{b_{2}}\right)$

In this case a small fraction of current flows in the main valve through the period which stars from the natural commutation point until the first IGBT by-pass valve is fired. The first IGBT will conduct from $(\alpha+\gamma)$ to $\left(\alpha_{b_{2}}+\gamma_{b_{2}}\right)$ and from $\alpha_{c_{2}}$ to $\alpha_{c_{1}}$. The second IGBT by-pass valve is conducting from $\left(\alpha_{\mathrm{b}_{2}}+\gamma_{\mathrm{b}_{2}}\right)$ to $\alpha_{c_{2}}$. Finally the main thyristor valve will conduct one more time from $\alpha_{c_{1}}$ to $\left(\frac{5 \pi}{6}+\alpha\right)$. Output DC voltage for this case is given in (6). 


$$
\begin{aligned}
V_{d}=\frac{3}{\pi} \sqrt{6} V_{p h}\left[\frac{1}{4}\right. & \left(2+n_{1}\right) \cos (\alpha+\gamma)+\frac{1}{\sqrt{3}} \sin (\alpha+\gamma)+\frac{1}{2} \cos \alpha \\
& +\frac{1}{4}\left(2+n_{1}\right) \cos \left(\alpha_{b_{1}}+\gamma_{b_{1}}\right)-\frac{1}{4 \sqrt{3}} n_{1} \sin \left(\alpha_{b_{1}}+\gamma_{b_{1}}\right) \\
& +\frac{1}{2} n_{2} \cos \left(\alpha_{b_{2}}+\gamma_{b_{2}}\right)-\frac{1}{2 \sqrt{3}} n_{2} \sin \left(\alpha_{b_{2}}+\gamma_{b_{2}}\right) \\
& \left.-\frac{1}{2}\left(n_{1}+n_{2}\right) \cos \alpha_{c_{2}}+\frac{1}{2 \sqrt{3}}\left(n_{1}+n_{2}\right) \sin \alpha_{c_{2}}\right]
\end{aligned}
$$

The cases (1, 2 and 3) are shown in Figure 3(a), Figure 3(b), and Figure 3(c) respectively.

d. For $\left(\alpha<\alpha_{\mathrm{b}_{2}}<\alpha+\gamma-\gamma_{\mathrm{b}_{2}}\right)$ and $\left(\alpha_{\mathrm{b}_{2}}<\alpha_{\mathrm{b}_{1}}\right)$

The second IGBT will conduct from $(\alpha+\gamma)$ to $\alpha_{c_{2}}$. Then the first IGBT is conducting from $\alpha_{c_{2}}$ to $\alpha_{\mathrm{c}_{1}}$. Finally, the main thyristor valvewill conduct again from $\alpha_{\mathrm{c}_{1}}$ to $\left(\frac{5 \pi}{6}+\alpha\right)$. DC voltage for this case is given in (7).

$$
\begin{aligned}
V_{d}=\frac{3}{\pi} \sqrt{6} V_{p h}[( & \left.\frac{1}{4}+n_{1}+n_{2}\right) \cos (\alpha+\gamma)+\frac{1}{2 \sqrt{3}}\left(\frac{1}{2}+n_{1}+n_{2}\right) \sin (\alpha+\gamma) \\
& +\frac{\sqrt{3}}{2} \cos \alpha-\frac{1}{2 \sqrt{3}}\left(\frac{1}{2}+n_{1}+n_{2}\right) \sin \left(\alpha_{b_{2}}+\gamma_{b_{2}}\right) \\
& -\frac{1}{2} n_{1} \cos \alpha_{c_{1}}+\frac{1}{2 \sqrt{3}} n_{1} \sin \alpha_{c_{1}}+\frac{1}{2} n_{2} \cos \alpha_{c_{2}} \\
& \left.+\frac{1}{2 \sqrt{3}} n_{2} \sin \alpha_{c_{2}}\right]
\end{aligned}
$$

e. For $\left(\alpha+\gamma<\alpha_{b_{1}}<\alpha_{c_{1}}-\gamma_{b_{1}}\right.$ and $\left.\alpha_{b_{1}}+\gamma_{b_{1}}<\alpha_{b_{2}}<\alpha_{c_{2}}-\gamma_{b_{2}}\right)$

This case is the normal case and in this case the main thyristor valve will conduct from $(\alpha+\gamma)$ to $\left(\alpha_{b_{1}}+\gamma_{b_{1}}\right)$. The first by-pass IGBT will conduct from $\left(\alpha_{b_{1}}+\gamma_{b_{1}}\right)$ to $\left(\alpha_{b_{2}}+\gamma_{b_{2}}\right)$. Then the second IGBT will conduct from $\left(\alpha_{b_{2}}+\gamma_{b_{2}}\right)$ to $\alpha_{c_{2}}$. The first IGBT will conduct again from $\alpha_{c_{2}}$ to $\alpha_{c_{1}}$. Finally, the main valve will conduct again from $\alpha_{c_{1}}$ to $\left(\frac{5 \pi}{6}+\alpha\right)$. Output DC voltage is given in (8), the commutation angles $\gamma, \gamma_{\mathrm{b}_{1}}$ and $\gamma_{\mathrm{b}_{2}}$ are given in (9), (10) and (11) respectively.

$$
\begin{aligned}
& V_{d}=\frac{3}{\pi} \sqrt{6} V_{p h}\left[\frac{1}{2} \cos (\alpha+\gamma)+\frac{1}{2} \cos \alpha\right. \\
& +\frac{1}{2} n_{1} \cos \left(\alpha_{b_{1}}+\gamma_{b_{1}}\right) \\
& -\frac{1}{2 \sqrt{3}} n_{1} \sin \left(\alpha_{b_{1}}+\gamma_{b_{1}}\right) \\
& +\frac{1}{2} n_{2} \cos \left(\alpha_{b_{2}}+\gamma_{b_{2}}\right) \\
& -\frac{1}{2 \sqrt{3}} n_{2} \sin \left(\alpha_{b_{2}}+\gamma_{b_{2}}\right) \\
& -\frac{1}{2} n_{2} \cos \alpha_{c_{2}}-\frac{1}{2} n_{1} \cos \alpha_{c_{1}} \\
& \left.+\frac{1}{2 \sqrt{3}} n_{1} \sin \alpha_{c_{1}}\right] \\
& \gamma=\cos ^{-1}\left[\cos \alpha-\frac{X_{C} I_{d}}{\sqrt{6} V_{p h}}\right]-\alpha \\
& \gamma_{b_{1}}=\cos ^{-1}\left[\cos \left(\frac{\pi}{6}+\alpha_{b_{1}}\right)-\frac{X_{b_{1}} I_{d}}{\sqrt{2} n_{1} V_{p h}}\right]-\left(\frac{\pi}{6}+\alpha_{b_{1}}\right)
\end{aligned}
$$




$$
\gamma_{b_{2}}=\cos ^{-1}\left[\cos \left(\frac{\pi}{6}+\alpha_{b_{2}}\right)-\frac{X_{b_{2}} I_{d}}{\sqrt{2} n_{2} V_{p h}}\right]-\left(\frac{\pi}{6}+\alpha_{b_{2}}\right)
$$

The cases (4 and 5) are shown in Figure 4(a) and Figure 4(b) respectively.
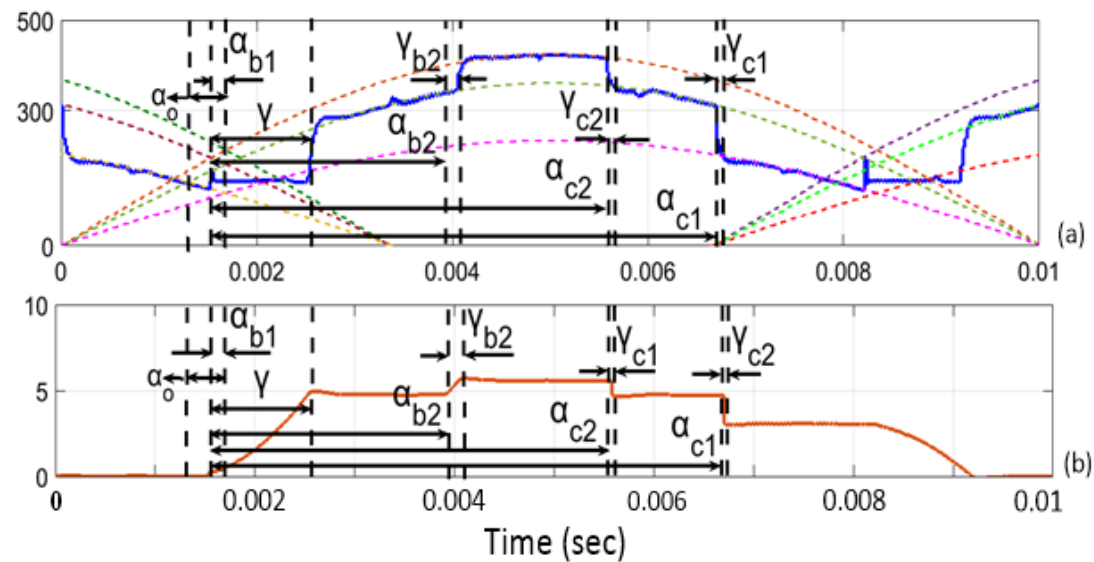

(a)

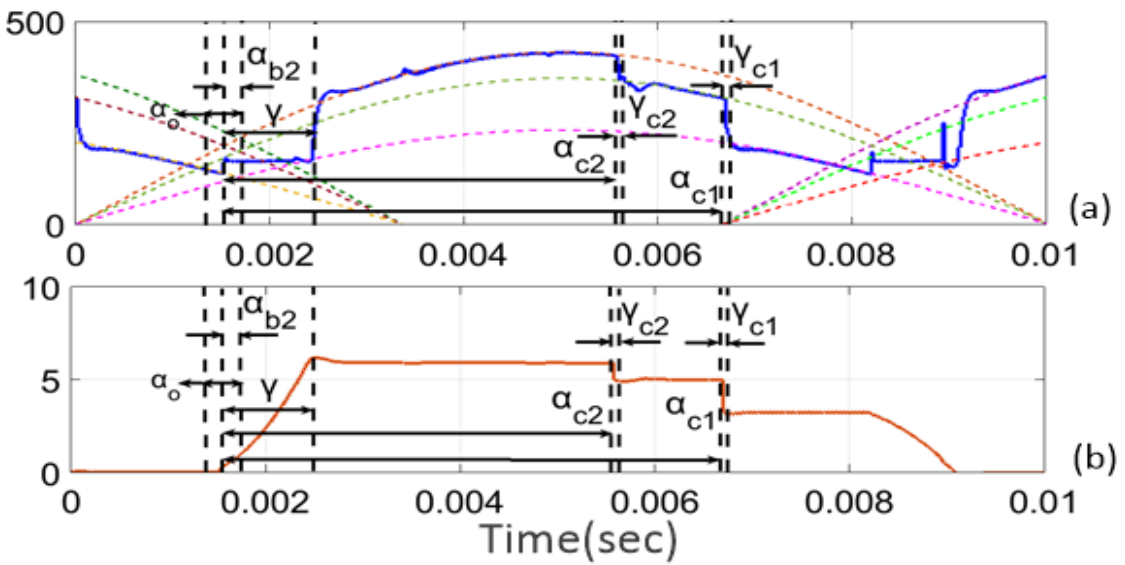

(b)
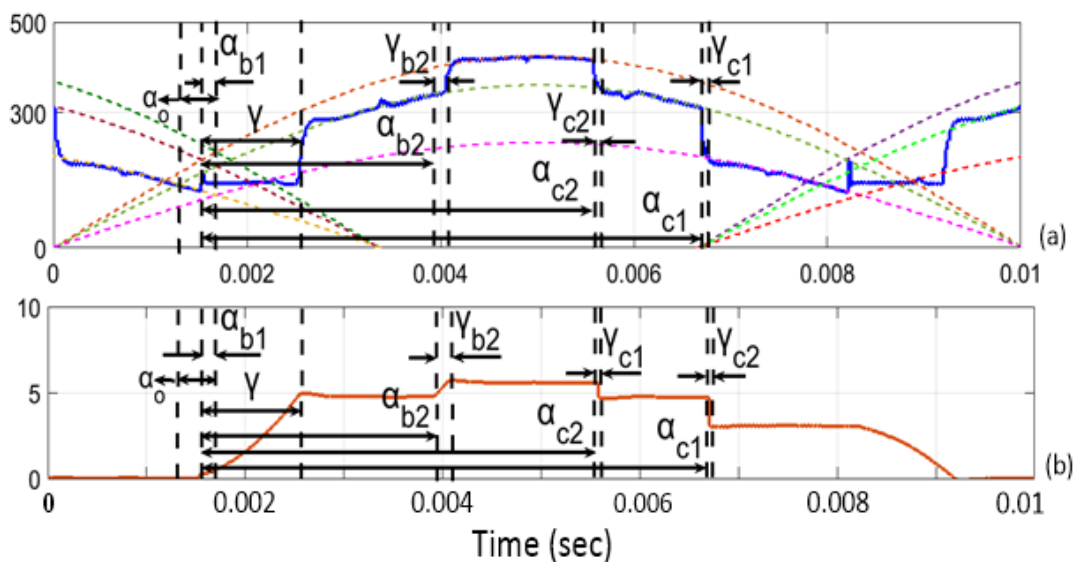

(c)

Figure 3. Voltage and current waveforms of rectifier with two by-pass IGBT valves at commutation reactance, $X_{c}=3 \Omega, \mathrm{n}_{1}=0.3, \mathrm{n}_{2}=0.15$ : (a) $\left(-\alpha_{\mathrm{o}} \leq \alpha_{\mathrm{b}_{1}}<0^{\circ}\right)$ and $\left(0<\alpha_{\mathrm{b}_{2}}<\alpha_{\mathrm{c}_{1}}\right.$, (b) $\left(-\alpha_{\mathrm{o}}<\alpha_{\mathrm{b}_{2}}<0^{\circ}\right)$ and $\left(\alpha_{\mathrm{c}_{1}}>\alpha_{\mathrm{c}_{2}}\right)$, and (c) $\left(-\alpha_{\mathrm{o}}<\alpha_{\mathrm{b}_{2}}<0^{\circ}\right)$ and $\left(\alpha_{\mathrm{c}_{1}}>\alpha_{\mathrm{c}_{2}}\right)$ 


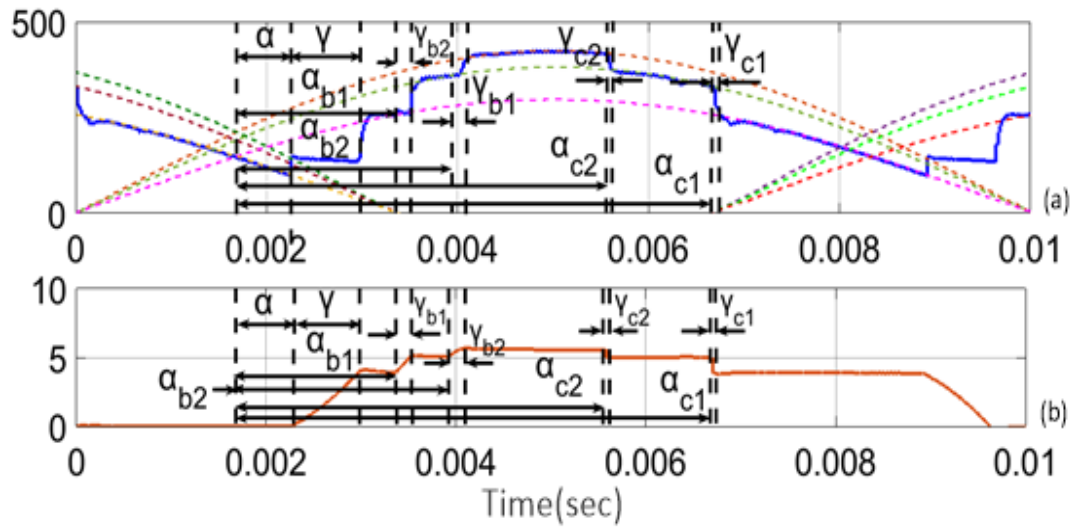

(a)

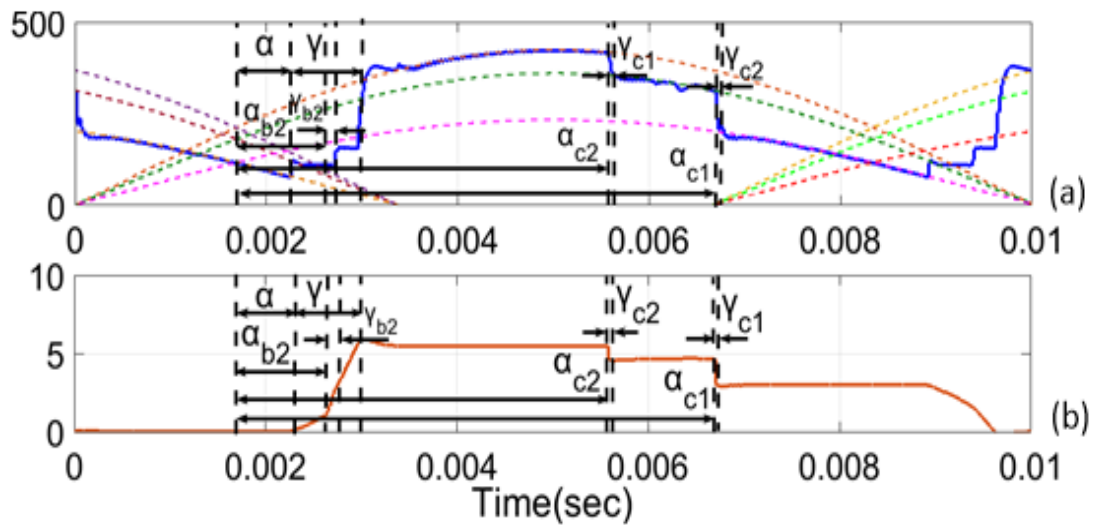

(b)

Figure 4. Voltage and current waveforms of rectifier with two by-pass IGBT valves at commutation reactance, $X_{c}=3 \Omega, \mathrm{n}_{1}=0.3, \mathrm{n}_{2}=0.15$ : (a) $\left(\alpha<\alpha_{b_{2}}<\alpha+\gamma-\gamma_{b_{2}}\right)$ and $\left(\alpha_{b_{2}}<\alpha_{b_{1}}\right)$, and (b) $\left(\alpha+\gamma<\alpha_{b_{1}}<\alpha_{c_{1}}-\gamma_{b_{1}}\right.$ and $\left(\alpha_{b_{1}}+\gamma_{b_{1}}<\alpha_{b_{2}}<\alpha_{c_{2}}-\gamma_{b_{2}}\right)$

\section{REACTIVE VOLT-AMPERE AND POWER FACTOR}

Figure 5 shows the reactive volt-ampere absorption of the three cases against the turn-on firing angles at different values of $X_{c}$. Figure 5(a) for impedance $X_{c}=0 \Omega$ and Figure 5(b) for impedance $X_{c}=1 \Omega$. Figure 6 shows the power factor of the three cases versus the turn-on firing angles at different values of $X_{c}$. Figure 6(a) for impedance $X_{c}=0 \Omega$ and Figure 6(b) for impedance $X_{c}=1 \Omega$. It can be seen that the reactive power is the least and the power factor are the highest in the converter with two IGBTs. The THD for different values for the reactance $X_{c}$ for the conventional converter, modified converter using one IGBT and modified converter using two IGBTs is shown in Table 1.

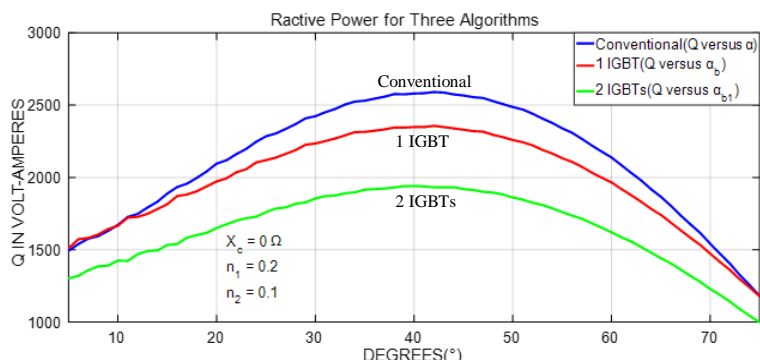

(a)

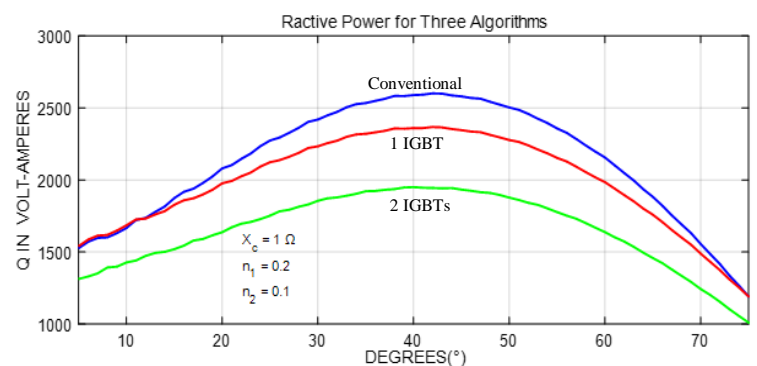

(b)

Figure 5. Reactive volt-ampere for the three algorithms at different impedance, $X_{c}(\Omega)$ for (a) reactance $X_{c}=0 \Omega$, and (b) reactance $X_{c}=1 \Omega$ 


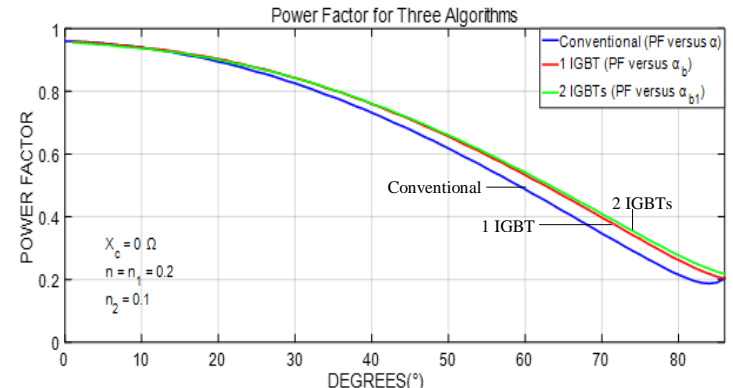

(a)

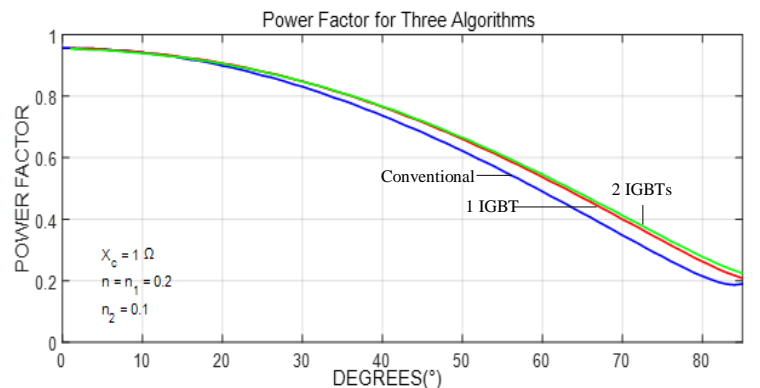

(b)

Figure 6. Power factor for the three algorithms versus the turn-on firing angles at different commutation reactance, $X_{c}(\Omega)$ : (a) for reactance $X_{c}=0 \Omega$ and (b) for reactance $X_{c}=1 \Omega$

Table 1. AC current THD for three algorithms

\begin{tabular}{cccc}
\hline Different $X_{c}(\Omega)$ at $\alpha=5^{\circ}$ & $\begin{array}{c}\text { Conventional } \\
\text { Converter }\end{array}$ & $\begin{array}{c}\text { AC current THD for three schemes (\%) } \\
\text { Modified converter with one }\end{array}$ & $\begin{array}{c}\text { Modified converter with } \\
\text { two IGBTs }\end{array}$ \\
\hline 0 & 30.7 & 27.68 & 25.86 \\
1 & 28.93 & 26.7 & 24.56 \\
3 & 27.37 & 25.59 & 23.92 \\
5 & 26.1 & 24.67 & 23.35 \\
Different & Conventional Converter & Modified converter with one & Modified converter with \\
& & IGBT & 22.82 \\
at $X_{c}=1 \Omega$ & 26.93 & 25.59 & 24.02 \\
$0^{\circ}$ & 27.97 & 26.7 & 26 \\
$5^{\circ}$ & 28.93 & 28.51 & 26.72 \\
$10^{\circ}$ & 32 & 31.44 & \\
$30^{\circ}$ & & & \\
\hline
\end{tabular}

\section{CONCLUSION}

Fast and continuous control of the DC voltage is obtained with minimum values of the firing angles of the main thyristors. The DC output voltage can be controlled by the firing angles of the two by-pass IGBT valves, in this paper the analysis is made at different values of these angles. The DC voltage may be varied over a range of $29 \%$, eliminates the need of the on-load tap-changer. The main advantage is that the VAR absorption is generally reduced, with more reduction in the VARs when a turn-off facility (i.e. IGBT) is included. The power factor using the modified converter with two by-pass IGBT valves is improved.

\section{REFERENCES}

[1] M. H. Rashid, Power Electronics Handbook, Academic press series in engineering, Academic press, 2001.

[2] J. Isozaki, K. Suzuki, W. Kitagawa, and T. Takeshita, "PWM strategies with duality between current and voltage source AC/DC converters for suppressing AC harmonics or DC ripples," in 2016 IEEE Energy Conversion Congress and Exposition (ECCE), Sep. 2016, pp. 1-8, doi: 10.1109/ECCE.2016.7855373.

[3] C. A. Munoz and I. Barbi, "A new high-power-factor three-phase AC-DC converter: analysis, design, and experimentation," IEEE Transactions on Power Electronics, vol. 14, no. 1, pp. 90-97, Jan. 1999, doi: 10.1109/63.737596.

[4] A. Suzuki and H. Akagi, "HVDC circuit breakers combining mechanical switches and a multilevel PWM converter: verification by downscaled models," IEEE Transactions on Power Electronics, vol. 34, no. 5, pp. 4259-4269, May 2019, doi: 10.1109/TPEL.2018.2863694.

[5] T. Shimizu, Y. Jin, and G. Kimura, "DC ripple current reduction on a single-phase PWM voltage-source rectifier," IEEE Transactions on Industry Applications, vol. 36, no. 5, pp. 1419-1429, 2000, doi: 10.1109/28.871292.

[6] S. Wang, K. H. Ahmed, G. P. Adam, A. M. Massoud, and B. W. Williams, "A novel converter station structure for improving multiterminal HVDC system resiliency against AC and DC faults," IEEE Transactions on Industrial Electronics, vol. 67, no. 6, pp. 4270-4280, Jun. 2020, doi: 10.1109/TIE.2019.2926036.

[7] R. Wang et al., "A high power density single-phase PWM rectifier with active ripple energy storage," IEEE Transactions on Power Electronics, vol. 26, no. 5, pp. 1430-1443, May 2011, doi: 10.1109/TPEL.2010.2090670.

[8] Y. Song et al., "Reducing the fault-transient magnitudes in multiterminal HVdc grids by sequential tripping of hybrid circuit breaker modules," IEEE Transactions on Industrial Electronics, vol. 66, no. 9, pp. 7290-7299, Sep. 2019, doi: 10.1109/TIE.2018.2881941.

[9] D. Shu, Z. Ouyang, and Z. Yan, "Multirate and mixed solver based cosimulation of combined transient stability, shiftedfrequency phasor, and electromagnetic models: A practical LCC HVDC simulation study," IEEE Transactions on Industrial Electronics, vol. 68, no. 6, pp. 4954-4965, Jun. 2021, doi: 10.1109/TIE.2020.2988228.

[10] A. G. Peter and K. A. Saha, "Comparative study of harmonics reduction and power factor enhancement of six and 12 -pulses HVDC system using passive and shunt APFs harmonic filters," in 2018 International Conference on the Domestic Use of Energy (DUE), Apr. 2018, pp. 1-10, doi: 10.23919/DUE.2018.8384395. 
[11] N. Mishra, P. Jain, and M. Patted, "Inductive filtering converter in HVDC light systems," International Journal of Engineering Development and Research (IJEDR), vol. 4, no. 1, pp. 183-187, 2016

[12] Z. Du, Y. Yang, J. Yang, J. Chen, T. Sun, and H. Mao, "Study on DC side harmonic performance of VSC HVDC," in 2020 IEEE Sustainable Power and Energy Conference (iSPEC), Nov. 2020, pp. 982-989, doi: 10.1109/iSPEC50848.2020.9350960.

[13] H. D. Al-Majali and D. O'Kelly, "Control of an HVDC converter using by-pass valves," 25th UPEC. Robert Gordon's Institute of Technology, vol. 1, pp. 325-328, 1990.

[14] D. O'Kelly, "Differential firing-angle control of series-connected HVDC bridges," Electric Power Systems Research, vol. 20 , no. 2, pp. 113-120, Feb. 1991, doi: 10.1016/0378-7796(91)90056-S.

[15] H. D. Al-Majali, "Voltage control of modified series-connected HVDC bridges," Electric Power Systems Research, vol. 43, no. 1, pp. 37-44, Oct. 1997, doi: 10.1016/S0378-7796(97)01157-7.

[16] H. D. Al-Majali, "Voltage control of modified series-connected HVDC bridges using GTO thyristor by-pass valves," Electric Power Systems Research, vol. 49, no. 2, pp. 79-86, Mar. 1999, doi: 10.1016/S0378-7796(98)00071-6.

[17] P. Briff, J. C. Zalalza, J. Nichols and K. Vershianin, "Turn-off delay compensation of series-connected IGBTs for HVDC applications," IEEE Transactions on Power Electronics, vol. 35, no.11, pp. 11294-11298, 2020.

[18] J. C. Zabalza, D. R. Trainer, J. C. Nichols and C. C. Davidson, "Balancing Algorithm for a self-powered high-voltage switch series connected IGBTs for HVDC applications," IEEE Transaction on Power Electronics, vol.34, no. 9, pp. 8481-8490, 2019.

[19] Mohammad. Ahmad and Sheeraz. Kirmani, "Performance analysis of LMS based control algorithm for power quality improvement in three-phase grid connected system for linearl non-linear load, "International Journal of Power Eletronics and Drive System. Vol. 10, No. 4, pp 1944-1950, 2019

[20] K. Friedrich, "Modern HVDC PLUS application of VSC in modular multilevel converter topology," in 2010 IEEE International Symposium on Industrial Electronics, Jul. 2010, pp. 3807-3810, doi: 10.1109/ISIE.2010.5637505.

[21] Y. Xue and X.-P. Zhang, "Reactive power and AC voltage control of LCC HVDC system with controllable capacitors," IEEE Transactions on Power Systems, vol. 32, no. 1, pp. 753-764, Jan. 2017, doi: 10.1109/TPWRS.2016.2557342.

[22] N. Parida and A. Das, "Modular multilevel DC-DC power converter topology with intermediate medium frequency AC stage for HVDC tapping," IEEE Transactions on Power Electronics, vol. 36, no. 3, pp. 2783-2792, Mar. 2021, doi: 10.1109/TPEL.2020.3015708.

[23] P. Bakas et al., "Review of hybrid multilevel converter topologies utilizing thyristors for HVDC applications," IEEE Transactions on Power Electronics, vol. 36, no. 1, pp. 174-190, Jan. 2021, doi: 10.1109/TPEL.2020.2997961.

[24] B. Li et al., "An improved transient traveling-wave based direction criterion for multi-terminal HVDC grid," IEEE Transactions on Power Delivery, vol. 35, no. 5, pp. 2517-2529, Oct. 2020, doi: 10.1109/TPWRD.2020.2971103.

[25] B. Li, X. Zhao, D. Cheng, S. Zhang, and D. Xu, "Novel hybrid DC/DC converter topology for HVDC interconnections," IEEE Transactions on Power Electronics, vol. 34, no. 6, pp. 5131-5146, Jun. 2019, doi: 10.1109/TPEL.2018.2866415.

[26] C. M. Diez, A. Costabeber, F. Tardelli, D. Trainer, and J. Clare, "Control and experimental validation of the series bridge modular multilevel converter for HVDC applications," IEEE Transactions on Power Electronics, vol. 35, no. 3, pp. 2389-2401, Mar. 2020, doi: 10.1109/TPEL.2019.2929862.

[27] J. Chivite-Zabalza, D. R. Trainer, J. C. Nicholls, and C. C. Davidson, "Balancing algorithm for a self-powered high-voltage switch using series-connected IGBTs for HVDC applications," IEEE Transactions on Power Electronics, vol. 34, no. 9, pp. 8481-8490, Sep. 2019, doi: 10.1109/TPEL.2018.2889375.

[28] J. Yang, Z. He, J. Ke, and M. Xie, "A new hybrid multilevel DC-AC converter with reduced energy storage requirement and power losses for HVDC applications,” IEEE Transactions on Power Electronics, vol. 34, no. 3, pp. 2082-2096, Mar. 2019, doi: 10.1109/TPEL.2018.2839117.

[29] M. N. Ambia, K. Meng, W. Xiao, A. Al-Durra, and Z. Y. Dong, "Adaptive droop control of multi-terminal HVDC network for frequency regulation and power sharing," IEEE Transactions on Power Systems, vol. 36, no. 1, pp. 566-578, Jan. 2021, doi: 10.1109/TPWRS.2020.2999443.

[30] J. Pedra, L. Sainz, and L. Monjo, "Three-port small signal admittance-based model of VSCs for studies of multi-terminal HVDC hybrid AC/DC transmission grids," IEEE Transactions on Power Systems, vol. 36, no. 1, pp. 732-743, Jan. 2021, doi: 10.1109/TPWRS.2020.3003835.

[31] A. Bidadfar et al., "Power system stability analysis using feedback control system modeling including HVDC transmission links," IEEE Transactions on Power Systems, vol. 31, no. 1, pp. 116-124, Jan. 2016, doi: 10.1109/TPWRS.2015.2407192.

[32] N.-T. Trinh, M. Zeller, K. Wuerflinger, and I. Erlich, "Generic model of MMC-VSC-HVDC for interaction study with AC power system," IEEE Transactions on Power Systems, vol. 31, no. 1, pp. 27-34, Jan. 2016, doi: 10.1109/TPWRS.2015.2390416.

[33] Abedalgany. Athamneh and B. H. Al-Majali, "Voltage stability enhancement for large scale squirrel cage induction generator based wind-turbine using statcom," International Journal of power Electronics and Drive Systems, vol.12, no.3, pp. 1784-1794, 2021

[34] H. D. Al-Majali, “Abnormal Harmonics generated by modified HVDC converter," Electric Power Components and Systems, vol. 35, no. 6, pp. 639-654, Mar. 2007, doi: 10.1080/15325000601139567.

[35] H. D. Al-Majali, B. H. Al-Majali, and Z. S. Almajali, "Reduced harmonics generated and reactive volt-ampere absorption of HVDC converter using by-pass switch,” WSEAS Transactions On Systems And Control, vol. 15, pp. 218-227, Jun. 2020, doi: 10.37394/23203.2020.15.23

[36] H. D. Al-Majali and S. M. Al-Dhalaan, "Transient of modified HVDC converters," Electric Power Systems Research, vol. 77, no. 10, pp. 1329-1336, Aug. 2007, doi: 10.1016/j.epsr.2006.10.002.

[37] H. D. Al-Majali and B. H. Al-Majali, "Fast and continuous control of a modified HVDC converter," WSEAS Transactions on Systems and Control, vol. 14, pp. 326-332, 2019. 